\title{
On the Influence of Seasonal Variation on Sports Tourism
}

\author{
Wei Wu, Huawei Liu \\ Physical Education College, Yanshan University, Qinhuangdao, 066004, China
}

Keywords: Tourism seasonality, Change, Sports tourism, Skiing, Natural human, Space conditions

\begin{abstract}
As the ordinary ornamental tourism, sports tourism is $t$ influenced by the seasonal influence, and because of the special requirements of the space, time and environment, the influence is even greater. This paper take skiing tourism as subject, which is popular with the ice and snow sports fans, detailed discussed the effects of various factors on the skiing tourism.
\end{abstract}

\section{Introduction}

Skiing tourism has been the most attractive form of sports tourism in the northern region. The development of ice and snow tourism project started earlier, with a very rich mass foundation and a wide range of enthusiasts, is the main choice for the winter tourism in the northern region. As a result of the skiing movement has the double characteristics of experience and movement, it also brings certain technical and economic constraints in technology and equipment, and it needs special time and space conditions. So the skiing movement is greatly restricted by the influence of the tourism seasonality.

\section{Seasonal analysis of Tourism}

\section{The cause of formation of tourism seasonality}

The cause of the formation of tourism is a lot of factors, which can be attributed to natural factors and institutional factors. Natural factors is the Seasonal periodicity brought by the cycle of the four seasons, such as rain, snow, wind, temperature and humidity changes. Natural factors can directly affect people's travel choice and pleasure, and as some specific tourism projects also require people to travel in a specific time; for system factors, the institutional factors is the social customs and norms brought by the seasonal effects, such as race, religion, leave, culture, economy and politics, etc. .

In our country, the cause of the seasonal tourism has always been classified into two categories: the two factors theory and many factors theory. The two factor is reflected by the natural factors and social factors mentioned above, domestic scholars believe that the two factor directly constitute the seasonal tourism. And the multi factor is further subdividing of the two factor, such as the tourism motivation, tourism behavior, tourism resources characteristics and human factors, which are four aspects of tourism seasonality. The cause of the formation of the tourist season is in three aspects: tourist, tourism resources and tourism industry. They can interact each other, and the seasonal variation decides the traveling time of the tourists, and the tourism influences the management of tourism and the seasonal choice of the tourism resources. So we will look at the dependency relation of the three in a dialectical view [1].

\section{The concrete manifestation of the seasonal tourism}

Seasonal tourism has the characteristics that occur repeatedly in the same place of tourism, and it is in units of one year. There are many objective conditions to determine the tourist season, such as tourism resources, climate conditions, tourist market, geographical location and transportation and so on. From a professional point of view, the main points of the seasonal tourism is divided into three forms.

\section{No peak season}

The most urban tourism area is this kind of seasonal type, because the attraction of urban tourism is business services and human history, rarely involves the natural factors, so the annual passenger traffic is average. Especially in the south, the four seasons is not clearly defined, the non-peak seasonal pattern is more obvious. 


\section{Single peak Seasonal pattern}

In coastal cities and coastal areas, the single peak seasonal tourism is more common, in a single peak seasonal environment, every year, there will have a Tourist traffic peak for one month, and concentrated in the 5 9 months. For example, Qingdao, Dalian and other coastal cities, the experiential tourism and sightseeing will be in the peak period of the year.

Multi peaks seasonal pattern

Multi peak seasonal tourism is mainly based on ornamental Tourism, which may exist a number of tourist peak in a year. In Beijing, Shanghai, Guangzhou and other places, because every year there are many major international events, so will have different groups of tourists. Under normal circumstances, the double peaks seasonal pattern is more common, such as Beijing, Guangzhou and other places. The three peak and even more the seasonal tourist area is very rare, it need the rich content of the tourism.

\section{The influence of seasonal changes on Sports Tourism}

As mentioned above, sports tourism will be limited by time and space, so the tourism seasonal fluctuation will bring a great influence of Ecological, economic, social and cultural for the sports tourism industry. Generally speaking, the academic circles has a lot of research on the negative impact of the three major elements of tourism, while the study of the positive impact is very little, because people hope to improve the development of tourism industry by studying and avoiding some negative effects. So this paper analyzes the impact of seasonal changes on the sports tourism from four aspects: ecological, economic, social culture and tourist perception.

\section{economic impact}

Economy refers to the economy of tourism. In the study of the economic impact of the tourism industry German sociologist Baum, said: there has a large number of tourist facilities will be shut down in the off-season, and reducing its effective utilization. Take ski tourism as case, the annual cost of tourism and depreciation have the opportunity to recover in the peak tourist season, so the existence of a huge pressure on the operation of ski tourism is not difficult to understand. In the northern region, many cities hope that through their ice and snow resources to seek benefits, but many areas of ice and snow tourism projects cannot receive a satisfactory return. Nagano and Niigata in Japan is a famous ski resort, but in recent years, both the ski tourism is in declining trend, this is due to the improvement of urban service industry level.

Because most people will choose the mature modern service, coupled with the stagnation of the investment of the ski industry in Japan, a series of chain reaction caused the sluggish domestic ice snow tourism service industry. When the charm of the ski resort is falling, the tourism industry is starting to look for new ways, such as cheap competition. But through the development of recent years, cheap competition not has brought a turning point for Japan's ski tourism industry, but let the industry into a more awkward situation, the income is still low and profit margins are also significantly reduced, which further reduce the level of skiing tourism service, resulting a very difficult to reverse the vicious circle. Of course, the impact of tourism on the economy is not only the negative, some scholars believe that the tourism seasonality will produce some positive elements, they are good for the economic benefits of skiing tourism. They can also attract visitors by changing its project in the off-season, such as Canadians who have a passion for ice and snow, their Quebec province will build indoor ski resorts in the summer, ice hockey, and ice skating, and so on. Sports tourism facilities to attract tourists to participate, although the investment may be larger, but they are need this kind of ski tourism has no seasonal industry, to ensure that their market has not been forgotten because of a few months of the off-season.

\section{Ecological impact}

American Ecological scholar Butler has said that " for longer-term, the seasonality Tourism region is better than no-obvious seasonality Tourism region." This sentence can be understood as that the off-season of Tourism is not a bad thing for the tourism industry, it is a good opportunity for the tourism ecological restoration. This view is very important for the enterprises engaged in the ski tourism, because the ski field is the ecological resources in the open air, it also needs the annual 
ecological restoration in the summer, thus ensuring the new season better tourism resources. This is also the relative theory of tourism resources, although tourism resources can be used repeatedly, but people in the use of it, but also have a certain bottom line, not over exploitation and utilization, we should pay attention to the protection and maintenance of ecological environment.

\section{Social and cultural influences}

Skiing tourism is a kind of sports tourism project which combines the natural and the humanities. The spread of ski culture contributed to the emotional communication and cultural exchanges between people, so it can be derived a variety of cultural services. The author believes that this kind of influence is more humane. But in the peak season of skiing tourism, is often the high incidence of traffic accidents, crime. The impact of this seasonal human factor has always been difficult to solve, its management costs are high, it is difficult to focus on management.

\section{The effect of tourist perception}

Skiing tourism attract the majority of ski enthusiasts, the objective of this part of the tourists are relatively fixed, and they have no obvious effect on the busy season or off-season. But for some beg recreational skiing tourism lovers, To jack up price in the busy season will lead to low interest of this part of the tourists, impression of tourism is greatly reduced. In addition, in the peak season, visitors will also product service in short supply, traffic congestion cannot improve satisfaction. in the off-season, many tourism will be because of lack of operating experience, unprofitable and forced to close their doors. So the seasonal impact of tourists has brought a huge impact. Seasonal influence has brought a huge impact to the tourists, the influence of perception determines the prosperity of tourism. This is a closed-loop structure of interaction, but also a test of the tourism industry of sports tourism.

\section{Development strategy of skiing tourism projects based on seasonal considerations}

\section{Rich ski tourism service project}

Besides skiing, the tourism industry should also enrich their surrounding the project, such as ski shops, cafes, restaurants, indoor ice and snow sports and spa and so on. Let visitors in the search for skiing can also enjoy leisure services, formed a comprehensive service system, so as to attract more fans to come. In the north of our country, in recent years, the "ski + hot spring" Service project is implemented, Its main operating process is alpine skiing - the cable car - the restaurant - HouShan Spa Hotel, the system allows visitors to experience the sport and leisure high quality service.

\section{Promote the development of ice and snow culture}

To break the impact of seasonal changes, the most should do is to promote the relevant sports culture, so that visitors feel the sports culture, love sports culture. In the Changchun city since 2003, every year held Vassar International Ski Festival organized by the city government. More than 20 countries in the world to participate, there is no lack of world-class champion. Such a big snow activities will naturally attract most ski enthusiasts. In fact, this is the kind of cultural extension. Constructed the sports tourism industry chain with sports, tourism, shopping, dining and other services, It also broke the influence of seasonal changes on sports tourism, and realized the characteristics of Changchun city in sports tourism industry, but also has a long-term sustainable development characteristics..

\section{Pay attention on the cultivation of professional service personnel for skiing tourism}

In the peak season of skiing tourism, good service can make the seasonal impact smallest, to bring more benefits for the tourism industry. Skiing is a very high professional requirements, so the tourism management department should pay attention to the cultivation and improvement of the professional quality of their own service personnel, in the selection of personnel to do fine selection, in the work stage should pay attention to their professional knowledge training, and to provide the most professional auxiliary service to visitors, ensure the safety of visitors in the ski. On this point, China in 2002 also began to perform the "China ski field place management standards", hoping to improve the safety of the person, to ensure the quality of service. 


\section{Rational allocation of sports tourism resources}

Ski tourism projects are strongly dependent on natural resources, so the northern cities must achieve the integration of development, cooperation, resource sharing and exchange of resources, and through the linkage mechanism to strengthen the advantages of each other in the ice and snow tourism resources, and achieve complementary advantages, but also achieve common interests. This is also a major factor to break the influence of seasonal changes on sports tourism.

Summary: This paper discusses the impact of seasonal changes on the sports tourism in the perspective of skiing tourism. It should be said that the negative factors is majority in seasonal change, but we should also see the positive side of the development of sports tourism projects, and face the negative impact of seasonal changes, and actively innovate, it is possible to form a strong operation and industry chain, to contribute to regional economic development.

\section{Acknowledgments}

This paper is Social Science Fund Project of Hebei Province in 2015, Which name is Research on the seasonal influence of sports tourism in Hebei province and the countermeasures to solve it (number: HB15TY002).

\section{References}

[1] Qiu Jianhui. The research on the Seasonal spatial differences and the influencing factors of inbound tourism of the hot spots in China. East China Normal University, 2014,19-24.

[2] Guo Xin. Research on the regional characteristics and development trends of the Japanese ski tourism, 2014,21-24.,

[3] Zhang Liangzhu. Influence of Changchun Jingyuetan vasa ski festival of ice and snow tourism industry. factors of Northeast Normal University, 2011.19-21. 